\title{
Attitudes versus Actions: The Relationship of Verbal and Overt Behavioral Responses to Attitude Objects
}

\author{
Allan W. Wicker ${ }^{1}$ \\ University of Wisconsin, Milwaukee
}

Gordon Allport (1954) has described the attitude concept as "the primary building stone in the edifice of social psychology [p. 45]," and the extensive attitude literature in the past 20 years supports this contention. Stimulated primarily by the cognitive consistency theories, thousands of pages have been written recently on attitude formation and change.

One possible reason for the popularity of the attitude concept is that social psychologists have assumed that attitudes have something to do with social behavior. Cohen (1964), in the concluding chapter of his book, Attitude Change and Social Influence, states:

${ }^{1}$ The writer is indebted to the following colleagues for helpful suggestions and comments on an earlier version of this paper: Roger Barker, L. B. Kornreich, Eugene Levitt, and Lawrence Linn. Thanks are also due to Anthony Fazio and James Green who supplied unpublished studies for review, and to Dean Bolton and Douglas Simpson for library work. Locating relevant references was facilitated by Deutscher's bibliography (1966a). This research was supported by a grant from the Graduate School of the University of Wisconsin-Milwaukee and National Institute of Mental Health Grant 1 R03 MH-15798-01. Portions of this paper were presented at the Western Psychological Association Convention, Vancouver, B.C., June 20, 1969.

Now at the University of Illinois, Urbana. 
Most of the investigators whose work we have examined make the broad psychological assumption that since attitudes are evaluative predispositions, they have consequences for the way people act toward others, for the programs they actually undertake, and for the manner in which they carry them out. Thus attitudes are always seen as precursors of behavior, as determinants of how a person will actually behave in his daily affairs [pp. 137-138].

But as early as 1934, there was published evidence contrary to the assumption that attitudes and behaviors are closely related. In the 1930's when, according to studies of social distance, there was much anti-Chinese sentiment in the United States, LaPiere (1934) took several extensive automobile trips with a Chinese couple. Unknown to his companions, he took notes of how the travellers were treated, and he kept a list of hotels and restaurants where they were served. Only once were they denied service, and LaPiere judged their treatment to be above average in $40 \%$ of the restaurants visited. Later, LaPiere wrote to the 250 hotels and restaurants on his list, asking if they would accept Chinese guests. Over $90 \%$ of the 128 proprietors responding indicated they would not serve Chinese, in spite of the fact that all had previously accommodated LaPiere's companions.

The present paper examines several aspects of the relationship between attitudes and actions: (a) importance of the relationship in terms of conceptual, validational, and social considerations, (b) empirical research on the relationship, and (c) factors postulated to influence the relationship.

Before continuing, it will be necessary to consider several terms. Following Insko and Schopler (1967, pp. 361-362), attitudes are conceived as "evaluative feelings of pro or con, favorable or unfavorable, with regard to particular objects"; the objects may be "concrete representations of things or actions, or abstract concepts." No distinction will be made between affective and cognitive components of attitude, since in practice both are tapped by verbal measures, and often questions about feelings and beliefs are included in the same attitude scale. The term overt behavior will be used to refer to nonverbal behavior outside the situation in which attitudes were measured. As Kendler and Kendler (1949) have noted, "attitude-behavior consistency" and "attitudebehavior inconsistency" are rather imprecise terms applied by an observer of verbal and overt behavioral responses. That is, they involve a judgment by the observer, and do not directly refer to social behaviors. 


\section{Importance of Attitude-Behavior Relationships}

\section{Conceptual Considerations}

In a discussion of "attitude as a scientific concept," DeFleur and Westie (1963) state that there are two general conceptions of attitude in the current literature, probability conceptions and latent process conceptions. The primary difference between them is "the kinds of inferences their proponents would derive from the behavior referent (observable attitudinal responses) [p. 20]":

The primary inference implied in probability conceptions is that attitudinal responses are more or less consistent. That is, a series of responses toward a given attitudinal stimulus is likely to show some degree of organization, structure, or predictability. Responses of a specified type, say verbal rejection behavior, may be more likely to occur than, say, acceptance or indifference responses for a given individual when he is confronted repeatedly with a defined attitude stimulus. If this is the case, such a response organization can be termed a negative attitude. The attitude, then, is an inferred property of the responses, namely their consistency. Stated in another way, attitude is equated with the probability of recurrence of behavior forms of a given type or direction.

The second type of attitude conception, the latent process view, begins with the fact of response consistency, but goes a step beyond this and postulates the operation of some hidden or hypothetical variable, functioning within the behaving individual, which shapes, acts upon, or 'mediates' the observable behavior. That is, the observable organization of behavior is said to be 'due to' or can be 'explained by' the action of some mediating latent variable. The attitude, then, is not the manifest responses themselves, or their probability, but an intervening variable operating between stimulus and response and inferred from the overt behavior. This inner process is seen as giving both direction and consistency to the person's responses [p. 21].

DeFleur and Westie argue that the latent process conception, which they describe as "by far the most popular," involves the assumption of attitude-behavior consistency. Since both verbal and overt behavioral responses are supposedly mediated by the same underlying, latent variable (attitude), then responses of a given kind (e.g., verbal) should both show consistency over time and covary with other kinds of responses (e.g., overt behavioral). And when verbal and overt behavioral responses do not correspond, one is left with the problem of determining which one is the better indicator of the latent attitude. Did LaPiere's hotel and restaurant owners have negative or positive attitudes toward Chinese? One would draw different conclusions depending upon 
which type of response he believed more accurately reflected the latent attitude. ${ }^{2}$

The assumption of attitude-behavior consistency is avoided in the probability conception since each kind of behavior "can be regarded as equally legitimate and the probability of each occurring under various circumstances, or their possible correlation, becomes an empirical problem [DeFleur \& Westie, 1963, p. 26]." If the proprietors' responses to letters do not correspond to their behaviors, one may conclude that there is no observed response consistency and thus no evidence that there is an attitude toward Chinese.

Proponents of the probability conception of attitude thus regard inconsistency as posing no conceptual problem since responses of different "kinds" or "universes" are involved (cf. B. F. Green, 1954; Kendler \& Kendler, 1949). Unfortunately, however, they often fail to specify criteria for determining when one response is of a different kind than another (Cook \& Selltiz, 1964). For example, is a verbal commitment to behave a different kind of response than actually engaging in the behavior?

A conception of attitudes which is in some ways similar to both the latent process and the probability notions has been proposed by Campbell (1963). He suggests that the same latent acquired behavioral disposition or attitude mediates both verbal and overt behavioral responses, but that the way the attitude is manifested depends upon certain situational pressures. Thus it may be easier to give a negative response on a mailed questionnaire than to refuse to serve a waiting Chinese couple. That is, the situational threshold for expressing negative feelings toward an ethnic group on a questionnaire may be lower than the threshold for denying them accommodations in a face-to-face situation.

Campbell argues that most notions of attitude-behavior inconsistency are too broad, and include instances of "pseudoinconsistency" in which verbal and overt behavioral responses do not correspond, yet are predictable if their thresholds are known. In LaPiere's study, inconsistency as Campbell conceives of it would occur only if persons who refused to accept Chinese in face-to-face encounters, indicated on a questionnaire that they would serve them. In Campbell's words, "The fact that $92 \%$ of the cases were mediocre in their Sinophilia, having enough to get over the low hurdle, but not enough to get over the high hurdle, is irrelevant to the problem of inconsistency, but rather speaks only as to the heights of the hurdles [p. 160]." Put another way, there were at

${ }^{2}$ See Mischel (1968) for an excellent treatment of this and related issues in the broader context of the measurement and validation of personality traits. 
least three levels of intensity of attitude toward Chinese: persons with the most favorable attitudes accepted Chinese both symbolically and in person, at the second level in favorability were those who accepted them face-to-face but not symbolically, the least favorable attitudes were shown by persons who rejected Chinese both symbolically and in person.

Campbell's conception resembles the probability notion described by DeFleur and Westie in that he apparently sees the task of specifying situational thresholds (which determine the degree of consistency of verbal and overt behavioral responses) as an empirical problem. At least he offers no a priori basis for categorizing situations in terms of the relative difficulty of expressing favorable or unfavorable attitudes. It should be noted that when situational thresholds are determined empirically, it is not sufficient merely to observe the percentages of people who pass each of two thresholds or "hurdles" and then to label as inconsistent only those who pass the higher threshold but not the lower one. The relative heights of thresholds determined from the responses of one sample must be cross-validated with a second group. The complexity of the problem of specifying quantifiable "heights" or thresholds for different situations is illustrated by the fact that in some studies (e.g., LaPiere, 1934) more people show unfavorable reactions to minority group members symbolically than in face-to-face interaction, while the reverse has also been reported (e.g., Linn, 1965).

\section{Validational Considerations}

It has been almost a quarter of a century since McNemar (1946) published a long review and critique of attitude-opinion methodology, yet many of his criticisms, particularly those on the validity of attitude measures, are applicable today. McNemar noted that although complex and "high sounding" definitions of attitudes are proposed, practically all attitude research is on the verbal level. The validity of attitude measures, i.e., "the degree of the relationship between overt nonverbal and verbal behavior [p. 296], " is not known, and apparently is of little interest to most investigators. "Some investigators have sidestepped the problem of validity by denying that anything exists beyond the verbal expressions, hence there is no problem of validity. Others have adopted the idea that scales or questions test whatever they test, so why worry [p. 297]." Research on the validity of verbal measures is, in McNemar's words, "direly needed."

Comparison of public opinion polls with voting behavior was cited by McNemar as relevant to the validity question, but he points out that this is validity only in a group sense. The per- 
centage of respondents indicating a preference for a candidate is compared with the percentage of vote; individual validity, i.e., the voting behavior of the particular respondents whose opinions were polled, is not determined.

In contrast to McNemar, and in keeping with their preference for the probability conception of attitude, DeFleur and Westie (1963) reject "the demands that those who construct attitude scales show the validity of their instruments by demonstrating that people behave overtly in a manner consistent with their verbal scale scores [p. 27]." Since "inconsistency between verbal scale scores and other overt actions is to be expected, then the use of external criteria for testing validity is ruled out [p. 27]." B. F. Green (1954) offers a similar view, stating that measures should be taken on the particular kind of "attitude universe" (e.g., verbal, action) in which one is interested, rather than using verbal measures on the assumption that they correlate highly with actions.

The difficulty in finding suitable overt behavioral measures with which to compare verbal measures has been noted by a number of writers (e.g., Corey, 1937; Murphy, Murphy \& Newcomb, 1937). One general approach to this problem has been to compare verbal and overt behavioral responses of persons assumed to be at the ends of an attitudinal continuum, e.g., attitudes toward prohibition by Methodists and businessmen. Investigations using this "known groups" approach have been criticized by Corey (1937) as providing only "indirect evidence almost of an anecdotal sort for the validity of attitude questionnaires [pp. 273-274]." He points out that the basis for selecting known groups is often their verbal behavior, rather than overt behavior, so that comparisons may be made, in effect, between two different verbal responses. The generality of validational studies using known groups is also limited by the facts that $(a)$ the range of the attitudinal responses within the groups is restricted, and $(b)$ only members of organized groups are studied. Persons with middling attitudes and those who are not members of organized groups are generally not available for study.

\section{Social Considerations}

Dollard (1949) has suggested that a high degree of consistency between words and acts has great "social utility":

It enables men to participate in organized social life with good confidence that others will do what they say they will do, will be where they say they will be. Valid prediction of behavior is not a mere luxury of morality, but a vital social necessity. Every man is under compulsion to keep his prom- 
ises, to make his acts correspond with his verbal expressions. He constantly watches others to see that they do likewise [p. 624].

The matching of opinions with more effortful behavior is not left to chance. Our children are given careful training in 'truthful' behavior. They are impressed with the social importance of keeping promises. They are trained in rehearsing directions received from parents and policed to see that they follow these directions correctly. It is probably this acknowledged training which gives us all the spontaneous confidence that verbal behavior on surveys very frequently predicts action in real life. No one can lie with impunity, that is, without anxiety, even to a surveyor [p. 625]

It may be that the training in our society leads the layman to expect attitude-behavior consistency. This expectation is particularly strong as it applies to public officials. Presumably it is very damaging to an elected official when it is shown that his voting behavior has not corresponded to his statements. This lack of predictability may imply that the person is insincere and not trustworthy. And civil rights leaders point up what they call the hypocrisy of many members of white society, who embrace the notions of equality and who express concern for minority groups, yet who fail to translate these feelings into positive programs.

Deutscher (1966b) raises another question relevant to the social significance of attitude-behavior relationships. He expresses concern that conclusions from social scientific research, which are primarily based on verbal responses, are guiding social action programs, which are primarily concerned with overt behavior. He asks rhetorically, "Can we assume that if we are attempting to alter behavior through a training program, an educational campaign, or some sort of information intervention, a measured change in attitude in the 'right' direction results in a change in behavior [pp. 250-251]?"

\section{Empirical Research on Attitude Behavior Relationships}

An attempt was made to locate studies which met the following criteria: $(a)$ the unit of observation must be the individual rather than a group, $(b)$ at least one attitudinal measure and one overt behavioral measure toward the same object must be obtained for each subject, $(c)$ the attitude and the behavior must be measured on separate occasions, and $(d)$ the overt behavioral response must not be merely the subject's retrospective verbal report of his own behavior. Studies relating changes of attitude to changes in overt behavior were not included. Although these criteria provide a rather stringent test of attitude-behavior relationships, they are compatible with the assumption cited by 
Cohen (1964) that attitudes have consequences for behavior outside the testing situation.

The studies are grouped into three categories on the basis of the attitude object: $(a)$ jobs, $(b)$ minority group members, and (c) miscellaneous objects. These studies are summarized below, greater detail being given for the studies most relevant to the later discussion of factors postulated to influence attitude-behavior relationships. A concise summary of all studies is given in Table 1. Coefficients of association when reported by the investigators are shown in the table. Unfortunately, in some instances investigators have reduced ordinal- and interval-scale data to dichotomies, and have not reported statistics of association. A common procedure is to select the top or bottom quartiles or halves of a distribution. Such a procedure not only fails to take full advantage of available data, but as Shontz (1965, p. 133) has noted, involves "an admission of lack of faith in the measurement of the variable."

For investigations not reporting a statistic of association, the percentage of subjects whose attitudes and behaviors were "consistent" was calculated from available data. Generally the percentage is the sum of the number of subjects who showed positive attitudes and positive behavior plus the number of subjects who showed negative attitudes and negative behavior, divided by the total number of subjects. Rarely were these percentages reported by the investigators. A word of caution about these percentage figures should thus be noted. For several studies, dichotomizing both attitudes and behaviors as positive or negative involved judgments with which others might disagree, and these judgments affect the magnitude of reported consistency. Also, the use of a percentage figure does not take into account the baseline level of behavior, e.g., in Dean's (1958) study, most labor union members did not attend union meetings, regardless of their attitude toward the union.

\section{Attitudes and Behaviors toward Jobs and Industrial Organizations}

Research on job attitudes and behaviors has recently been reviewed by Vroom (1964). The present section summarizes the data and conclusions from that review.

Perhaps the most common behavioral measure in industrial studies is job performance, as rated by the employee's supervisor. The rating is then related to the employee's job attitudes. Data on reliability of performance ratings are rarely reported, although split-half reliability coefficients of attitude measures are sometimes given.

Work performance. Vroom (1964) cites 15 studies relating job attitudes and performance of individuals in a wide range of occu- 


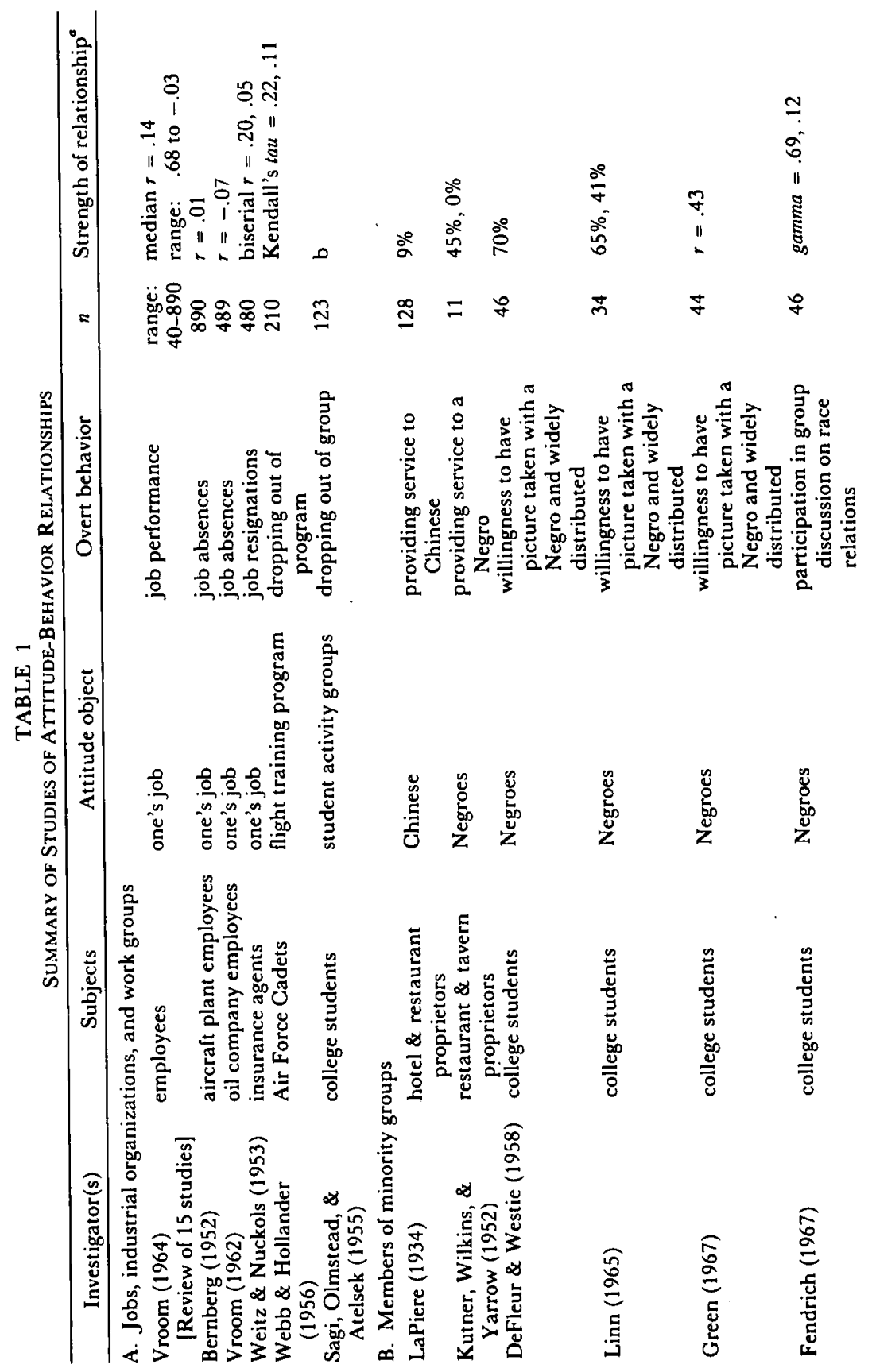




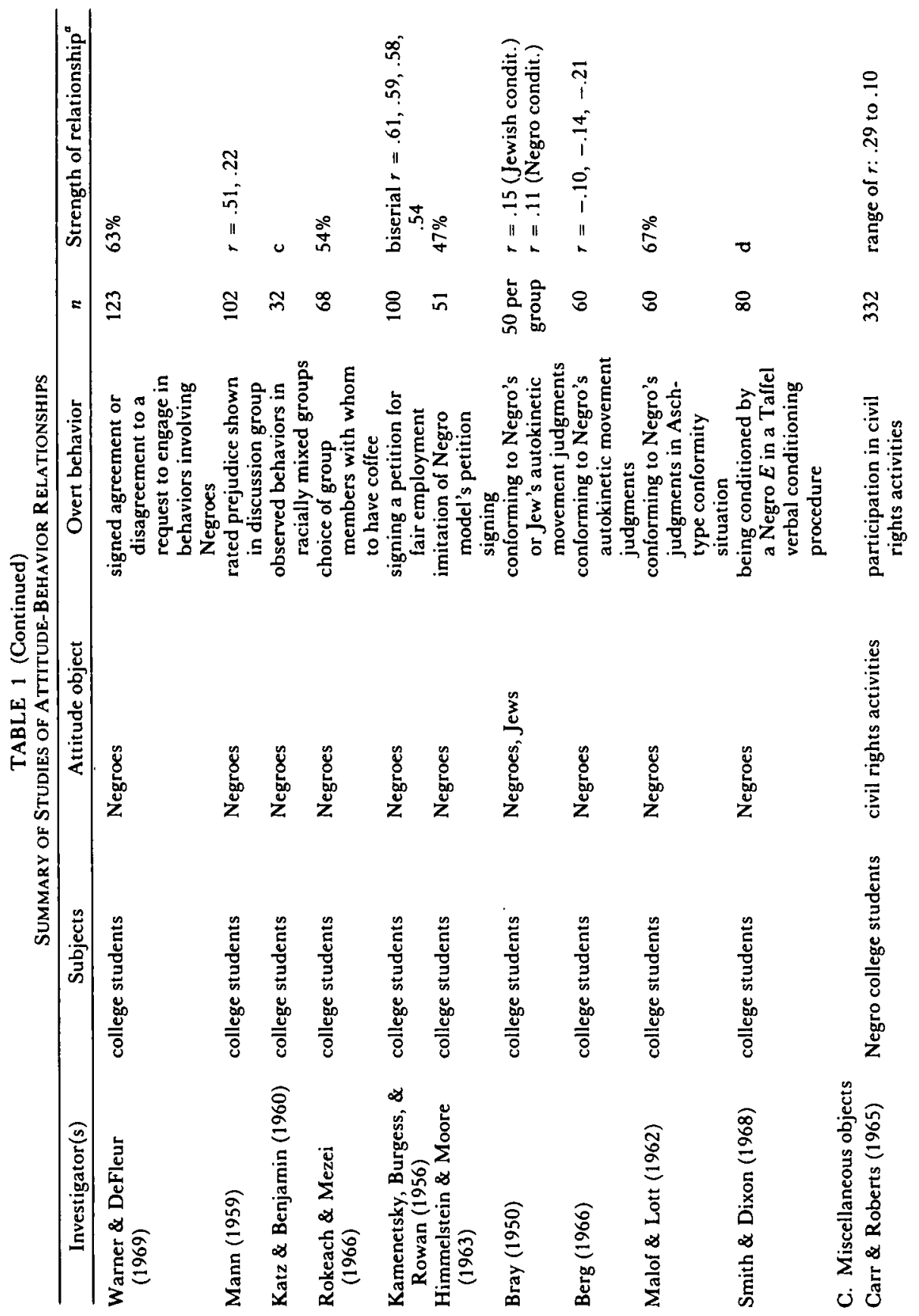




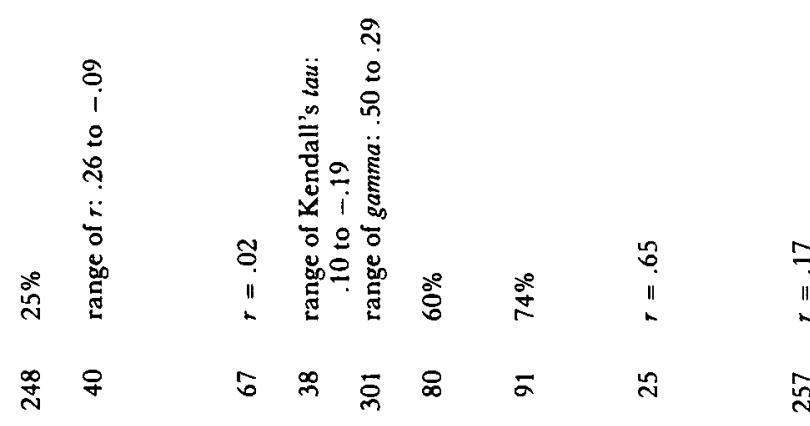

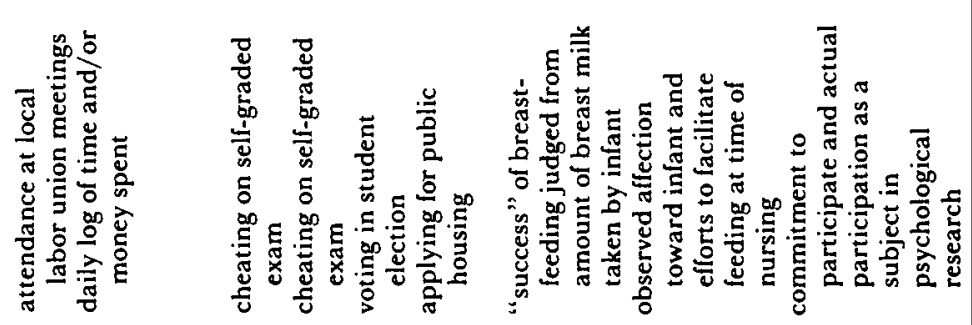
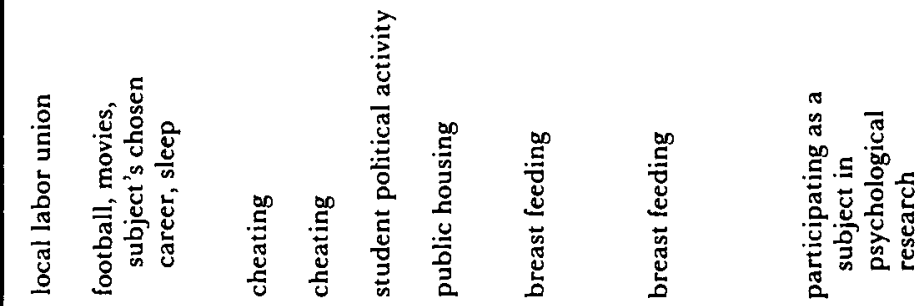

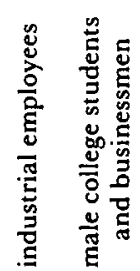
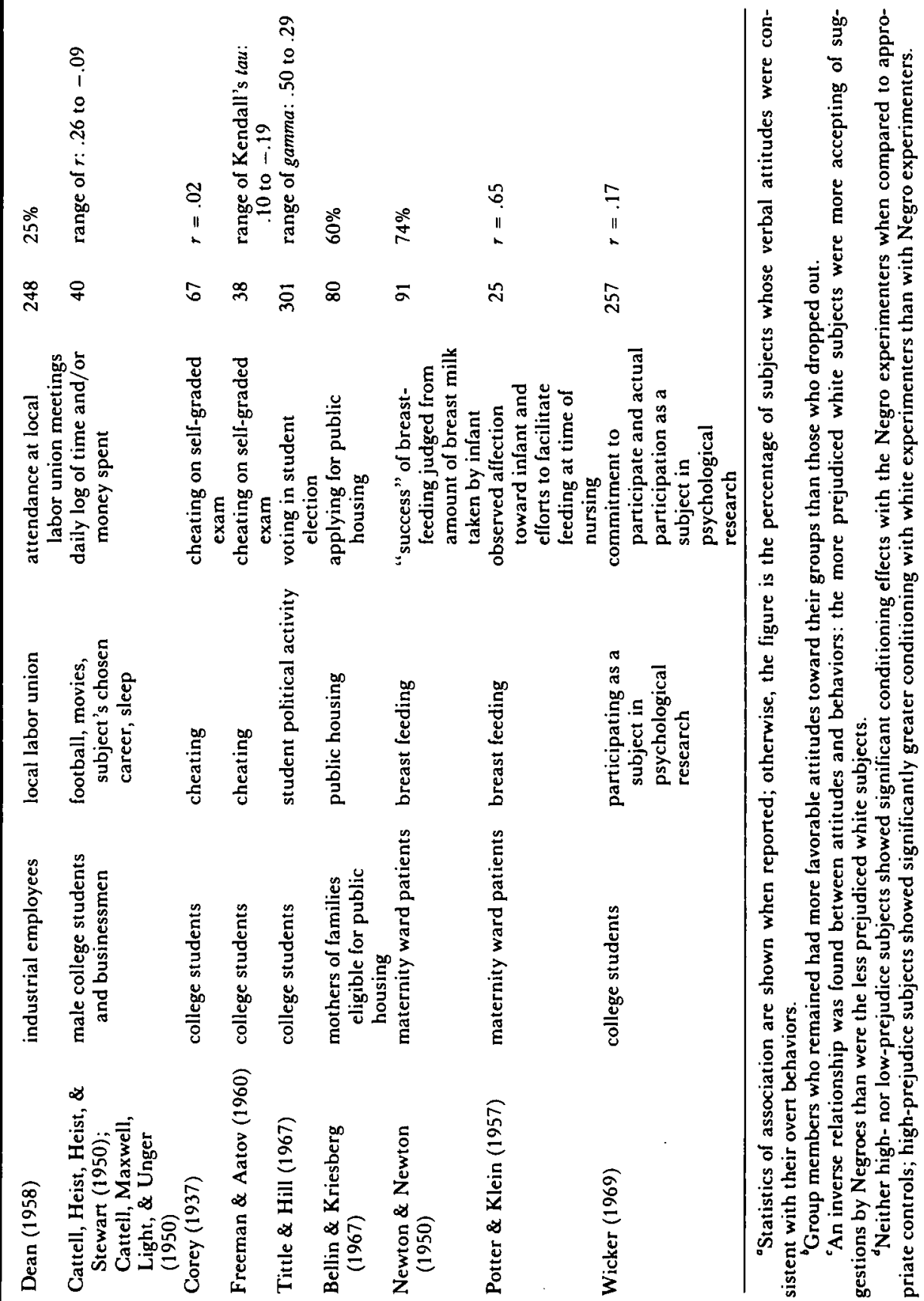
pations, including insurance agents, plumber's apprentices, farmers, supervisors in an electronics firm, female sales clerks, and others. The $\mathcal{N}$ 's for the studies ranged from 40 to 890 . For the 15 studies, the median product-moment correlation between job performance and attitudes is .14 , with a range of .68 to -.03 . Of these, only seven coefficients were significant beyond the .05 probability level. Moreover, the authenticity of the .68 coefficient, reported in an unpublished study, has been questioned by Brayfield and Crockett (1955, p. 401-402). The next highest coefficient is . 31 .

Work absences. Only two studies cited by Vroom (1964) clearly meet the criteria of the present review. Bernberg (1952) found no correlation between attitudes toward the company and absences for 890 hourly workers in an aircraft plant. Vroom (1962) reported a correlation of -.07 (ns) between job satisfaction and absences for 489 oil company employees. In both studies, absence data were obtained from company records.

Work resignations. Weitz and Nuckols (1953) sent questionnaires on job attitudes to 1235 insurance agents. Biserial correlation coefficients between these attitudes and job survival for the 480 agents who returned questionnaires were $.20(p<.01)$ for a direct attitude measure and .05 ( $n s)$ for an indirect measure. Webb and Hollander (1956) report a Kendall's tau of .11 between a questionnaire measure of attitudes toward a flight training program and voluntary continuation in the program among 210 cadets who had shown aptitude for flying. A self-ranking of interest in the program and survival yielded a tau of .22. Levels of significance are not reported for these figures. Sagi, Olmstead and Atelsek (1955) report that college students who remained as participants in student groups $(n=63)$ had significantly $(p<.003)$ higher personal involvement attitudes toward their group than students who dropped out $(n=60)$.

Thus the evidence from Vroom's (1964) review suggests that job attitudes have only a slight and often insignificant relationship with job performance and absences from work. The few available studies relating job attitudes with resignations tentatively suggest that these two variables may be more closely related.

\section{Attitudes and Behaviors toward Members of Minority Groups}

Providing public accommodations. The classic study by LaPiere (1934) described in the introductory section showed a considerable discrepancy between verbal responses and treatment of Chinese guests in restaurants and hotels. A similar study is reported by Kutner, Wilkins, and Yarrow (1952). Two white women entered 11 restaurants and taverns in a suburb of a North- 
eastern city, and after they were seated, a Negro woman joined them. The Negro was never refused admission, and the service in the establishments was described as "exemplary." The establishments visited were later asked by letter if they would take reservations for a social group which included Negroes. Seventeen days after the letters were sent, no replies had been received. Telephone calls were then made to the establishments, and as a result five managers tentatively and reluctantly agreed to take the reservations, and six refused. When control calls, not mentioning the race of guests, were made to the establishments, 10 immediately took the reservations.

Agreeing to be photographed. Three studies compared white college students' willingness to be photographed with Negroes with their responses to verbal attitude scales. DeFleur and Westie (1958) had 250 students respond to Summated Differences Scales (Westie, 1953) to obtain attitudes toward Negroes. Twenty-three students from the top quartile of the attitude score distribution (prejudiced group) and the same number from the bottom quartile (unprejudiced group) were then selected for further study. The two groups were matched on eight social background variables. As a part of an interview procedure, subjects were shown slides of a well-dressed Negro seated with a well-dressed white person of the opposite sex. The slides were used as a projective test. Later, subjects were asked if they would be willing to pose with a Negro of the opposite sex for the purpose of making a similar set of slides. A "standard photograph release statement" given to each subject contained a graded series of seven uses to which the photograph might be put: (1) laboratory use to be seen only by professional sociologists, (2) publication in a technical journal read only by professional sociologists, (3) laboratory use to be seen by a few dozen students, (4) as a teaching aid to be seen by hundreds of sociology students, (5) publication in the student newspaper in a story on the research, (6) publication in the student's hometown newspaper, (7) use in a nation-wide publicity campaign advocating racial integration. The subject signed his name for each use he agreed to. Responses for level of usage of the photographs were dichotomized into scores above and below the mean, and then were compared to the attitude measure. Of the 23 subjects with the most negative attitudes toward Negroes, five signed more than the average number of uses to which the photographs could be put; nine oi the 23 unprejudiced subjects signed fewer than the average number of uses. Although a chi-square analysis revealed a significant $(p<.01)$ relation between attitude and level of agreement, the proportion of inconsistent subjects (14 out of 46) seems large, considering that the sample was se- 
lected to represent the extremes of the verbal scale.

Linn (1965) attempted to improve upon the DeFleur and Westie (1958) design by (a) making the stimuli in the verbal and overt behavioral situations more similar, (b) reducing any influences on subjects due to the knowledge they were participating in an experiment, and $(c)$ making the behavior situation more credible by having Negroes present.

Students in introductory sociology courses completed an attitude questionnaire which included seven items regarding subjects' willingness to be photographed with a Negro of the opposite sex. The items represented essentially the same graded series of uses employed by DeFleur and Westie (1958). Thus Linn's attitudinal measure was the same as DeFleur and Westie's behavioral measure, except that the questions were posed as hypothetical and not actual commitments.

Four weeks later, female students who had completed the questionnaire were asked in class to volunteer for interviews conducted by a psychology testing organization interested in developing a semi-projective personality test. Thirty-four students volunteered. At the interview, the subject was told by the interviewer, a Negro, that the testing firm was developing a TAT which would show a racially integrated couple in various social situations. She was asked to pose for such photographs, and to sign photographic releases for four levels of use of the photographs by the testing company. At the close of the interview, the subject was introduced to a second Negro, who purportedly was representing an organization working on a racial integration campaign. The organization was thus interested in the photographs. The subject then was asked to sign three more photograph release agreements relating to the integration campaign. The seven levels of agreement were identical to items on the questionnaire which had been administered earlier. If the subject agreed to be photographed, an appointment was made to have the pictures taken, and when she appeared, the deception was explained.

On the attitude questionnaire, only two of the 34 subjects said they were not willing to pose with a Negro. However, in the actual situation, 12 subjects refused to sign any of the releases. Also, the mean number of release levels signed on the questionnaire was 4.9 compared to 2.8 in the behavior situation. Attitudebehavior discrepancies of two or more levels on the 7-point photograph release scale were shown by $59 \%$ of the sample. Generally, the larger discrepancies were for subjects who indicated on the questionnaire a willingness to have the photographs be widely used. 
In a study by Green (1967, 1969), an experimenter posing as a representative of a publishing firm told students in several college classes that his company needed photographs to include in textbooks it was developing. Later he distributed sketches of poses for the photographs. All poses included two persons, and they represented four different degrees of intimacy ranging from portrayal of "equality in a public situation" to "a fairly intimate heterosexual relationship." For each sketch there was an all-white version (both figures were white) and an inter-racial version (one figure was a Negro, the other a white). For both versions of each sketch, the subject was asked to indicate his willingness to pose as indicated in the sketch by signing four photographic releases. The releases varied in the degree to which the photograph would be disseminated, ranging from use in a Peace Corps textbook for underdeveloped countries to use in a Life magazine story concerned with Peace Corps textbooks. The dependent variable was the difference between the subject's signed commitment to the all-white and the inter-racial versions of each sketch. An additional independent variable was the social status of two Negroes who assisted the experimenter at the time the photograph release signatures were obtained. In the low status condition, they were sloppily dressed and shuffled about the room when distributing materials to subjects. In the high status condition, both were well-groomed and well-dressed and they were introduced as university students. It was thought that subjects would surmise that the two Negroes present would be the photographic models and thus they would be less willing to sign release statements for the inter-racial photographs in the low status condition.

In the following week, students were asked in their classes (by a different experimenter) to complete a number of questionnaires, including the Multifactor Racial Attitude Inventory (Woodmansee \& Cook, 1967) as a part of a "public opinion study of college students." The data analyzed were from 44 subjects who scored from .5 to 1.5 standard deviations from the mean (moderately favorable toward Negroes) or from -.5 to -1.5 standard deviations from the mean (moderately unfavorable) on the Inventory.

An analysis of variance of signed photograph releases indicated that (a) subjects with moderately favorable attitudes were more willing to be photographed with Negroes than were those with moderately unfavorable attitudes $(p<.01)$, (b) subjects were less willing to pose for the photographs portraying a high degree of intimacy between themselves and Negroes $(p<.05)$, and $(c)$ this effect of degree of intimacy was slight when the pho- 
tograph was to have a restricted dissemination, but was strong when many people would see the photograph $(p<.01)$. None of the other variables or interactions had a significant effect. It is also reported that the product-moment correlation coefficient between the attitude measure and the behavioral index was .43 $(p<.05)$.

Participating; in a civil rights discussion. Fendrich (1967) has related white college students' attitudes toward Negroes to their verbal commitment to interact with Negroes and their actual participation in discussion groups on racial problems. A scale of attitudes toward Negroes was individually administered to 46 students at their places of residence. At the time of the interview, the investigator also obtained responses to a commitment scale, which included questions on whether the subject would engage in a range of behaviors with a Negro, from having coffee with him to having him spend the weekend at the subject's home. In addition, "subjects were asked if they were willing to attend small group discussions with members of the NAACP that were scheduled in the near future [p. 352]." At the interview, approximately half of the subjects were given the commitment scale first, and the other half responded to the attitude scale first.

Within five days after the interview, subjects were contacted to see if they would attend one of four discussion meetings; those who did attend the meetings were asked at the end of the discussion to sign up for work on various civil rights projects. A fourpoint behavioral scale was thus available, ranging from refusing the invitation to participate in the discussion group through attending and signing up for further activities. It is not reported whether the interviewer contacted the subjects and led the discussion groups, or whether different persons performed these roles; thus the degree to which the experimenters were blind to the conditions is not known. Association between the attitude scale and the overt behavioral scale was calculated separately for the two groups: for subjects who responded to the attitude scale first, gamma $=.12(n s)$, and for those responding to the commitment scale first, gamma $=.69(p<.01)$. The gamma statistic represents the proportion of variance in overt behavior accounted for by the attitude measure. Thus, the obtained value of .69 for one group is quite high.

Making a commitment to interact. Warner and DeFleur (1969) recently employed a factorial design to examine the influence of several variables, including attitudes, upon overt behaviors toward Negroes. Subjects were 537 students in a border-state university in which the prevailing community norms were hostile to integration. On the basis of responses to a Likert attitude scale, subjects 
were categorized as low or high in prejudice. Subjects in each quartile of the attitude distribution were matched on nine social background and demographic variables. The investigators mailed to each subject a letter signed by the president of a fictitious student organization, and asking the recipient to make a commitment to engage in behavior involving Negroes. Half of the subjects were asked to participate in behaviors which allowed them to maintain status superiority over Negroes, e.g., go to homes of potential Negro college students to tell them about life as a college student. The other half received requests to engage in behaviors involving a reduction of social status differences between Negroes and whites, e.g., going on a date with a Negro student. All subjects were asked to sign a pledge that they would engage in the behavior, or if they preferred, to sign a statement that they would not engage in the behavior. For half the subjects in each condition the letter stated that the pledged actions would be published in the campus newspaper, while for the other half the letter assured subjects their pledge and subsequent actions would be kept confidential. The signed document was to be returned in a selfaddressed, stamped envelope which accompanied the letter.

Unfortunately, letters were returned by only 123 of the 537 subjects $(23 \%)$ making interpretation of the results somewhat difficult. The investigators report for each condition the difference between the percentage of subjects who signed a statement complying with the requested involvement with Negroes and the percentage who signed a statement refusing the requested involvement with Negroes. More of the responding low prejudice subjects complied than refused, while the opposite was true of the high prejudice subjects. More subjects complied than refused when the requests involved behaviors allowing subjects to maintain status differences; the opposite result was obtained when the requests involved behaviors requiring subjects to reduce status differences. And when subjects believed that their commitments would be made public, more refused than complied with the request; the opposite result was obtained for subjects told they would remain anonymous. Other analyses suggest that (a) low prejudice subjects tended to behave consistently (comply) when their behaviors were anonymous, while high prejudice subjects tended to behave consistently (refuse) when their behaviors were public, and (b) under the public condition, but not under the private condition, low prejudice subjects tended to behave consistently (comply) when the behaviors maintained status differences, while high prejudice subjects tended to behave consistently (refuse) when the behaviors reduced social status differences.

Interacting in small groups. Three studies have examined $\mathrm{Ne}$ - 
groes' and/or whites' responses to one another in group interactions. Mann (1959) had members of racially-mixed discussion groups rate one another on racial prejudice. Rated prejudice correlated $.51(p<.05)$ with the patriotism subscale of the $E$ Scale, and .22 (ns) with a sociometric measure. Katz and Benjamin (1960) found an inverse relationship between attitudes and behaviors in racially-mixed experimental groups: white subjects scoring high on the F Scale (high authoritarianism) "accepted significantly more suggestions from Negro subjects and rejected fewer" than those scoring low on the F Scale (p. 455). And Rokeach and Mezei (1966) have shown that both high- and lowprejudice subjects (as determined from responses to Negro items on the E Scale) tend to choose for future interactions persons who are similar in beliefs to themselves, regardless of the race of the individual.

Signing a petition. Kamenetsky, Burgess, and Rowan (1956) administered an attitude questionnaire dealing with "the desirability of legislative measures to abolish discrimination against Negroes in employment," along with a projective measure (a modification of the Rosenzweig Picture-Frustration test) to introductory psychology students. Three weeks earlier, the students had indicated in class whether they were willing to have their names printed on a petition to be sent to congressmen urging passage of a Fair Employment Practice Act. The attitude questionnaire was scored according to Likert, Guttman, and $H$ techniques. The biserial correlation coefficients relating attitudes with petition signing were $.61, .58$, and .59 , respectively $(n=100$, all $p<.001)$. For the projective measure, the corresponding coefficient was $.54(p<.001)$.

Accepting social influence. Several investigators have attempted to determine whether subjects' attitudes toward minority groups are related to their susceptibility to influence by minority group members. Himmelstein and Moore (1963) used a modeling situation in which a Negro or white confederate signed or refused to sign a petition before a naive white subject was asked to sign. The naive subject was categorized as high or low in prejudice on the basis of his responses to an "attitude scale adopted from the Authoritarian Personality." Imitative signing was found to be unrelated to the prejudice measure. Bray (1950) and Berg (1966) have studied the influence of minority group members on subjects' judgments of autokinetic movement. Bray (1950) reports a product-moment correlation coefficient of -.15 (ns) between subjects' attitudes toward Jews and the difference between their autokinetic movement judgments and those of a "Jewish" con- 
federate; for a corresponding Negro condition, the coefficient was $11(n s)$. Moreover, anti-semitic subjects conformed more to judgments by a "Jewish" confederate than to judgments by a "Gentile" confederate. Berg (1966) reports the following productmoment coefficients between the discrepancy of subjects' judgments and a Negro confederate's judgments and these verbal measures: F Scale, -.14; E Scale, -.21; Social Distance, -.10; none is significant.

Malof and Lott (1962) used an Asch-type conformity situation to determine the extent to which naive white subjects would be influenced by a Negro or white confederate who gave correct judgments of the length of lines in face of an erroneous judgment by an all-white majority. Subjects were rated as high or low in prejudice on the basis of $E$ Scale scores. The percentages of subjects giving correct judgments in agreement with the confederate were: high prejudice, white confederate, $80 \%$; high prejudice, Negro confederate, $47 \%$; low prejudice, white confederate, $67 \%$; low prejudice, Negro confederate, $80 \%$. The difference between the white and Negro confederate conditions for the high prejudice group is of borderline significance $(p=.10)$.

Smith and Dixon (1968) compared the effectiveness of white and Negro experimenters in verbally conditioning subjects' responses. A $2 \times 2 \times 2$ design was employed, with 2 categories each of race of experimenter, prejudice of subject (based on $E$ Scale responses), and experimental condition (conditioning or control). Attitude-behavior consistency would be demonstrated if high prejudice subjects gave more reinforced responses when the experimenter was white than when he was a Negro, and if the low prejudice subjects did not show differential effects due to race of experimenter. Although the obtained means were in the expected order, the three-way interaction was only of borderline significance $(p<.10)$. Further analyses revealed that high prejudice subjects gave significantly more of the reinforced responses to white experimenters than to Negro experimenters $(p<.05)$, but high and low prejudice subjects did not differ in the number of reinforced responses in the Negro experimenter condition.

The present review of attitudes and behaviors toward minority group members reveals little correspondence between the two types of variables, and in several cases there are reversals of expected relationships. The only striking exceptions to this overall conclusion are the studies by Green $(1967,1969)$, Kamenetsky, et al. (1956) and Fendrich (1967). In each of these studies, the behavioral measure or a commitment to behavior was obtained prior to the verbal measure. This point will be further discussed below. 


\section{Attitudes and Behaviors toward Miscellaneous Objects}

Participating in civil rights activies. A study by Carr and Roberts (1965) dealt with Negro American college students' attitudes and behaviors toward civil rights activities. Attitudes toward social action were measured on a Likert-type instrument. Subjects also rated the concept, "Negro college students who take part in civil rights demonstrations," on eight semantic differential evaluative scales.

Two behavioral measures were employed. One was a threelevel scale of participation in civil rights activities: no participation, participation short of "sitting in" or "demonstrating," and participation in at least one demonstration. This information was obtained by questionnaire and confirmed by student civil rights leaders. The second measure was the total number of times the subject had been involved in any kind of civil rights activity.

Correlation coefficients relating attitudinal and behavioral measures are reported separately for males $(n=104)$ and females $(n=228)$. Four attitude-behavior coefficients (two verbal by two overt behavioral measures) were reported for each sex. For the male sample, the $r$ 's ranged from .25 to .29 (all $p<.05$ ). For the female sample, the range was .10 to .25 (two coefficients of .10 were not significant).

Attending labor union meetings. Dean (1958) compared labor union members' attitudes with their attendance at local union meetings. An attitude questionnaire was mailed to 500 production workers, of whom 254 responded. Items included questions about the workers' attitudes toward unions in general and toward their local union. A researcher attended 9 out of 12 local union meetings during the year, keeping a record of attendance at each. Subjects were categorized on the behavioral measure as attenders $(n=43)$ or non-attenders $(n=205)$ depending on whether they had attended any of the nine observed meetings.

All attenders and $91 \%$ of the non-attenders were categorized as having positive attitudes toward unions in general on the basis of their responses to a single item. Local union leaders were seen by $57 \%$ of the attenders as doing a good job for the workers, compared to $34 \%$ of the non-attenders. Also, $62 \%$ of the attenders and $37 \%$ of the non-attenders thought that conditions had improved a great deal since the union came into the plant. To the question of whether workers felt union officers would push their grievances, $85 \%$ of the attenders and $69 \%$ of the non-attenders said yes. No statistical tests are reported for the above data.

Time and money spent in activities. Cattell and his colleagues (Cattell, Heist, Heist, \& Stewart, 1950; Cattell, Maxwell, Light, 
\& Unger, 1950) had subjects keep a log of the amount of time and money they expended upon certain activities (e.g., football, movies, their chosen career, sleep) over two-week periods. Product-moment correlation coefficients relating time and money spent with measures of attitude toward the activities ranged from .26 to -.09 .

Cheating on examinations. Corey (1937) administered weekly true-false examinations to 67 students enrolled in an educational psychology class. Each student graded his own exam in the following class period, after it had been accurately scored but left unmarked by the researcher. All test questions were true-false statements marked by the students with easily altered "pluses" and "minuses." The difference between each subject's reported test score and his actual score over five tests was his cheating score. The reliability coefficient of cheating behavior for the first two and last two tests was .65 .

Attitude toward cheating was measured by a highly reliable questionnaire scored by the Likert method. The correlation between cheating scores and attitudes toward cheating was .02 . However, it was found that the difference between subjects' true scores and the maximum possible score correlated with the cheating score .46. In Corey's words, "whether or not a student cheated depended in much larger part upon how well he had prepared for the examination than upon any opinions he had stated about honesty in examinations [p. 278]."

In a similar study, Freeman and Ataov (1960) related students' cheating to responses on four projective measures and one direct measure of attitudes toward cheating. None of the verbal measures was significantly related to cheating behavior; Kendall's tau ranged from .10 to -.19 .

Voting in a student election. In a study of attitudes and behaviors related to participation in student political activity, Tittle and Hill (1967) employed five different techniques to assess attitudes: Likert, Guttman, and Thurstone techniques, plus the semantic differential and a simple self-rating scale. Responses to a questionnaire incorporating these measures were obtained from 301 upperclass college students. The behavioral measure was whether the students had voted in an election held a week before the questionnaire was administered, as determined from voting records. The following gamma statistics relating voting behavior and attitudes were obtained: Likert (15 items), .50; Likert (10 items), .46; Guttman, .39; Thurstone, .32; semantic differential, .35; and self-rating scale, .29 . Similar coefficients were obtained when the authors related the attitude measures to self-reported voting behavior. 
Applying for public housing. Bellin and Kriesberg (1967) have related expressed interest in public housing with the act of applying for such housing. Their subjects were 79 mothers of families eligible for the housing; 21 of the respondents had already made applications at the time of the interview, and 12 others applied later. Although a number of verbal measures were obtained in the interviews, the data are not fully reported. Responses to three questions are reported in sufficient detail to be presented here: whether respondents were interested in applying for public housing, whether they felt that public housing apartments provided more for one's money than other kinds of housing, and whether friends and relatives would approve if the respondent moved into public housing.

The following are the percentages of subjects who expressed an interest in the housing: $100 \%$ of those who had already applied, $58 \%$ of those who later applied, and $39 \%$ of those who did not apply. Beliefs that public housing is more economical than other housing were expressed by $76 \%$ of those who had previously applied, $50 \%$ of those who later applied, and $61 \%$ of those who did not apply. The percentages of respondents who said friends and relatives would approve if they moved into public housing were: $85 \%$ of those who had already applied, $45 \%$ of those who later applied, and $27 \%$ of those who did not apply. The authors conclude that, whether used singly or in combination, their questions were not strong predictors of applying among those who had not already applied. They suggest that the more favorable attitudes toward public housing by those who had already applied probably resulted from modification of attitudes to be consistent with action already taken, although they acknowledge the tenability of the alternative explanation that more favorable attitudes led respondents to apply.

Breast feeding. Newton and Newton (1950) have investigated the relation of maternal attitudes toward breast feeding to success of breast feeding. Subjects were 91 maternity ward patients who had normal deliveries and who did not refuse to try to breast feed. Attitudes were determined by means of an interview, usually held within 24 hours of the delivery. Verbatim responses to the question, "how do you feel about breast feeding your baby?" were examined by two independent judges, who categorized subjects' attitudes as positive, indicating a desire or determination to breast feed; doubtful, indicating mixed feelings, indifference or indecision; or negative, indicating a preference for bottle feeding. The judges agreed in $93 \%$ of the cases.

Babies were taken to mothers six times a day. Until the fourth day after birth, a bottle always accompanied the baby to the 
mother. On the fourth day, the baby was weighed before and after being taken to the mother to determine how much milk it received from the breast. The mean amount of milk given at this feeding was $59 \mathrm{gm}$. for mothers with positive attitudes, $42 \mathrm{gm}$. for those with doubtful attitudes, and $35 \mathrm{gm}$. for mothers with negative attitudes. The difference between the positive and negative attitude groups and between the positive and doubtful groups are reported to be "significant," although the $p$ levels are not specified.

Success of breast feeding was also related to mothers' attitudes. The criterion for success was supplying sufficient milk by the fifth day after delivery that formula supplementation was not needed. The percentages of mothers in the three attitude categories who were successful at breast feeding were positive, $74 \%$; doubtful, $35 \%$; and negative, $26 \%$. The differences between the positive and negative groups and between the positive and doubtful groups are reported to be "highly significant." Only $2 \%$ of the mothers with positive attitudes had stopped all breast feeding attempts by the fifth day, compared with $18 \%$ of the doubtful group and $30 \%$ of the negative group.

Using other analyses, Newton and Newton attempt to show that the above differences between the various attitude groups were not due to mothers' experiences with laction with previous children or to the mother's judgment about the amount of milk in her breasts.

In another study conducted in a hospital maternity ward, Potter and Klein (1957) compared mothers' attitudes toward babies and their handling of new-born infants during breast feeding. Twenty-five mothers were observed with their babies during feeding periods on the second and fourth or fifth day post-partum. All mothers in the hospital were required to breast feed until discharged. Observed behaviors were recorded and later scored according to the degree to which affectionate and facilitative nursing behaviors were shown by the mother. Attitudes toward babies were determined from six interview questions, including an item on planned duration of breast feeding and a self-rating of maternal feeling. Although the authors do not report the correlation coefficient relating the two measures, Newton and Newton (1967) report it to be $.65(p<.001)$.

It may be, however, that this coefficient is inflated due to Potter and Klein's selectivity in choosing behaviors to correlate with their verbal measure. They report that a number of other, more general behaviors (such as whether mothers talked to their babies and how mothers reacted when the nurse came to take the baby at the end of the nursing period) "were not found to be a 
reliable index of attitude toward the infant [p. 42]." Moreover, it is not reported whether the observers, the interviewers, and the raters of behavioral and verbal protocols were blind with respect to the other data on the subjects.

Nine months after they left the hospital, 16 of the 25 mothers were again interviewed. All but one of the subjects scoring high on the attitude toward babies scale reported they had continued to nurse after leaving the hospital. Of those who ranked low on the attitude scale, all reported they had discontinued nursing immediately after leaving the hospital. The cutting points for high and low attitudes, and the number of subjects in each category, are not reported.

Participating in psychological research. Wicker (1969) has recently examined the relationship of students' attitudes toward research and their participation as subjects in psychological experiments. Subjects rated the following concepts on semantic differential evaluative scales: scientific research, psychological research, participating as a subject in psychological research, and Psychology Department's policy regarding students' participation as subjects in psychological research. Subjects were 257 students in two sections of an introduction to personality course. The Psychology Department's policy, which was read to the classes immediately before attitudes were measured, states that participation as a subject is voluntary, but those who do participate receive points which may be used to help determine the final course grade in borderline cases.

There were four levels of behavior, corresponding to steps in the recruitment process: (a) stated unwillingness to participate, (b) stated willingness to participate, but unwilling to schedule an appointment at any one of four times the subject had previously indicated he would be available, $(c)$ stated willingness to participate, appointment scheduled, but failure to appear for the experiment, and $(d)$ stated willingness, appointment scheduled, and appearance at the experiment. All behavioral measures were obtained one to four weeks after the attitude assessment. Productmoment correlation coefficients relating attitudes and participation behavior were as follows: scientific research, -.04 (ns); psychological research, .06 (ns); participation as a subject in psychological research, .17 $(p<.01)$; Psychology Department's policy regarding student participation in psychological research, $.19(p<.01)$.

\section{Summary of Empirical Studies}

The studies cited above have covered a wide range of subject populations, verbal attitude measures, overt behavioral measures, 
and attitude objects. Taken as a whole, these studies suggest that it is considerably more likely that attitudes will be unrelated or only slightly related to overt behaviors than that attitudes will be closely related to actions. Product-moment correlation coefficients relating the two kinds of responses are rarely above .30 , and often are near zero. Only rarely can as much as $10 \%$ of the variance in overt behavioral measures be accounted for by attitudinal data. In studies in which data are dichotomized, substantial proportions of subjects show attitude-behavior discrepancies. This is true even when subjects scoring at the extremes of attitudinal measures are compared on behavioral indices.

Several studies suggest that attitude-behavior consistency may be greater when the overt behavior or a behavioral commitment is assessed in advance of the attitude measurement (Bellin \& Kriesberg, 1967; Fendrich, 1967; Green, 1967, 1969; Kamenetsky, et al., 1965; Potter \& Klein, 1957). Explanations for such findings have been advanced by cognitive dissonance theorists (Brehm \& Cohen, 1962; Festinger, 1957) and a behaviorist (Bem, 1967). But there are also a number of studies in the present review in which behavioral measures preceded attitude assessment, and which show inconsistency (Dean, 1958; Freeman \& Aatov, 1960; Kutner, et al., 1952; LaPiere, 1934). Furthermore, if one's ultimate interest is overt behavior, prediction of attitudes from overt behaviors is of less interest than prediction of overt behavior from attitudes, which requires that verbal responses be measured first.

It may be argued by some that if the "proper" attitude measures are employed, greater consistency will result. For example, some might argue that measures of affect are best, and others might argue that beliefs or behavioral intentions are more closely related to overt behaviors. Such arguments are best evaluated by future investigation rather than examination of the research cited above. The verbal measures employed in the studies often are not described in detail; moreover, when details are available, it is often the case that a single measure may be based on some questions which seem to tap affect, and others which seem to tap beliefs and behavioral dispositions.

Insko and Schopler (1967) have suggested the possibility that much evidence showing a close relationship between verbal and overt behavioral responses has been obtained but never published because investigators and journal editors considered such findings "unexciting" and "not worthy of publication." If such data exist, their publication is needed to correct the impression suggested by the present review that attitude-behavior inconsistency is the more common phenomenon. 
The presently available evidence on attitude-behavior relationships does not seem to contradict conclusions by two early researchers in the area:

LaPiere wrote in 1934 :

The questionnaire is cheap, easy, and mechanical. The study of human behavior is time consuming, intellectually fatiguing, and depends for its success upon the ability of the investigator. The former method gives quantitative results, the latter mainly qualitative. Quantitative measurements are quantitatively accurate; qualitative evaluations are always subject to the errors of human judgment. Yet it would seem far more worth while to make a shrewd guess regarding that which is essential than to accurately measure that which is likely to prove quite irrelevant [LaPiere, 1934, p. 237].

Corey, in 1937 wrote:

It is impossible to say in advance of investigation whether the lack of relationship reported here between attitude questionnaire scores and overt behavior is generally true for measures of verbal opinion. Were that the case, the value of attitude scales and questionnaires would for most practical purposes be extremely slight. It would avail a teacher very little, for example, so to teach as to cause a change in scores on a questionnaire measuring attitude toward Communism if these scores were in no way indicative of the behavior of his pupils.

It is difficult to devise techniques whereby certain types of overt behavior can be rather objectively estimated for the purpose of comparison with verbal opinions. Such studies despite their difficulty, would seem to be very much worthwhile. It is conceivable that our attitude testing program has gone far in the wrong direction. The available scales and techniques are almost too neat. The ease with which so-called attitudinal studies can be conducted is attractive but the implications are equivocal. [Corey, 1937, p. 279].

\section{Factors Postulated to Influence Attitude-Behavior}

\section{Relationships}

Of course, most researchers employing the attitude concept do not accept the critical viewpoints cited above. They often argue that additional factors need to be taken into account in predicting overt behavior:

An attitude, no matter how conceived, is simply one of the terms in the complex regression equation we use to predict behavior; we cannot expect it to do too much. I think we must take seriously Lewin's formula, $\mathbf{B}=\mathbf{f}(\mathbf{P}, \mathbf{E})$. If the latent variable [attitude] is conceived as inside $\mathbf{P}$... one still needs to know the specific nature of the environment, the form of the function relating $\mathbf{P}$ and $\mathbf{E}$, and the other predispositions and their interactions with the one under consideration before one can accurately predict behavior. The embarrassing thing is that we have not systematically investigated these other sources of influence on overt behavior and not 
that we are unable to predict the overt behavior solely from the predisposition. [Weissberg, 1965, p. 424].

Apparently many writers agree with Weissberg that other sources of influence do contribute to variation in overt behavior. Often these factors are mentioned in discussion sections by investigators who failed to demonstrate attitude-behavior consistency. But most researchers do not seem to share Weissberg's embarrassment that the factors have not been systematically studied, since there are very few investigations (Green, 1967, 1968; Warner \& DeFleur, 1969) which relate any variable other than attitudes to the overt behaviors. And surprisingly, very few of the investigators who have empirically studied the attitudebehavior relationship have published more than one study in the area.

\section{Personal Factors}

In the remainder of the present paper, the factors which are most frequently mentioned as influences on behavior will be listed and discussed. But owing to the absence of systematic research, the arguments for the significance of each factor are often plausible anecdotes and post hoc explanations. Clearly, the greatest need in the attitude-behavior area is to operationalize and to test the contributions of the factors which have been offered as reasons for attitude-behavior inconsistency.

The factors to be discussed have been categorized as either personal (that is, individual difference, intrapersonal) factors or situational (extrapersonal, environmental) factors. The personal factors which will be discussed are other attitudes held by the individual; competing motives; verbal, intellectual, and social skills; and activity levels.

Other attitudes. A number of writers have argued that there are many attitudes or values relevant to any given behavior, and thus the relationship between the behavior and a single attitude may appear to be inconsistent because other attitudes have not been considered (cf. Cook \& Selltiz, 1964; Hyman, 1949; Insko \& Schopler, 1967; Newcomb, Turner \& Converse, 1965; Rokeach, 1967). Newcomb, et al. (1965) cite a public opinion survey conducted at the time of the 1956 presidential election (Campbell, Converse, Miller, \& Stokes, 1960). A national sample responded to six attitude objects: Eisenhower, Stevenson, Democratic party, Republican party, and party positions on domestic and foreign issues. Respondents also reported how they had voted. Reported voting behavior and attitude toward Eisenhower yielded a point biserial correlation coefficient of .52 . However, when attitudes toward all six objects were considered, the coefficient was .71. 
Insko and Schopler (1967) argue that while an overt behavior may appear to be inconsistent with a given attitude, the behavior may be consistent with one or more other attitudes which are more strongly held. Thus the person who has a favorable attitude toward the civil rights movement, but who does not contribute to it, may have an even more favorable attitude toward keeping a good credit rating, caring for the needs of his family, paying the rent on time, etc.

It may be noted that the "other attitudes" explanation has a behavioral parallel: There are many possible behaviors relevant to a given attitude, and if inconsistency is observed, it may be attributed to the failure to consider other behaviors.

Competing motives. Some writers (e.g., Cook \& Selltiz, 1964; Deutsch, 1949; Kendler \& Kendler, 1949) have suggested that motives or drives underlying a given behavior may be stronger than motives which are in some way related to a relevant attitude. These stronger motives can presumably range from persistent unconscious desires to temporary states of arousal, and can include both "normal" and "abnormal" responses.

Corey's (1937) finding that the number of test questions students missed was a better predictor of cheating behavior than their attitudes toward cheating could fit under the category of competing motives: subjects' motivations to improve their grades were more "potent" than their motivations to behave honestly.

Kutner, et al. (1952) have suggested that the prejudiced restaurant and tavern owners in their study experienced the competing motives of $(a)$ either refusing admission or service because they or their patrons were offended by Negroes or $(b)$ doing nothing and thus avoiding a disturbance.

Verbal, intellectual, and social abilities. It has been suggested that attitude-behavior inconsistency may result from the inability of the behaving individual to make the appropriate verbal or overt behavioral response (Deutsch, 1949; Dollard, 1949). Persons having low intelligence, poor hearing or reading ability may not understand the investigator's questions or instructions. Also, an individual may lack the ability or knowledge appropriately to translate his attitude into effective acts. Thus a person favoring social welfare legislation may fail to vote for a strong welfare advocate because he is unaware of the candidate's position. Sometimes social skills are lacking. Deutch (1949) suggests that people may not behave in a friendly manner because they do not know how to start being friendly or how to initiate an interaction.

Activity levels. Dollard (1949) has suggested that some instances of attitude-behavior inconsistency may be understood by considering the individual's overall activity level. Someone who 
is highly active may be more likely to act in ways consistent with his attitudes than "the apathetic individual who is more or less indifferent to the environment and does not act strongly to gain his ends [p. 630]."

\section{Situational' Factors}

Situational factors constitute the second broad class of variables postulated to influence overt behaviors and thus the degree of attitude-behavior consistency. Systematic research examining both personal and situational influences on overt behavior has shown that predictions of overt behavior can be made more accurately from knowledge of the situation than from knowledge of individual differences. Intrapersonal variables become important as predictors when their interactions with situational factors are considered. (See, for example, Barker, 1963, 1965; Barker \& Wright, 1955; Ellsworth, Foster, Childers, Arthur, \& Kroeker, 1968; Mischel, 1968; Rausch, Dittman, \& Taylor, 1959; Raush, Farbman, \& Llewellyn, 1960.) Thus it seems likely that efforts to operationalize and test situational factors will have a higher payoff than similar efforts on intrapersonal factors.

A general postulate regarding situational influences on attitude-behavior relationships is the following: The more similar the situations in which verbal and overt behavioral responses are obtained, the stronger will be the attitude-behavior relationship. The situational factors to be discussed may be thought of as potentially significant dimensions along which environments can vary from highly similar to highly dissimilar. These dimensions include the actual or considered presence of certain people, normative prescriptions of behavior, alternative behaviors available, specificity of attitude objects responded to, extraneous, unforseen events, and expected and/or actual consequences of various acts. Maximal similarity would exist when two situations were highly similar on all of the dimensions.

Actual or considered presence of certain people. Hyman (1949) has suggested that inconsistency between attitudes and behaviors should not be surprising if the verbal responses are obtained anonymously or under the pledge of secrecy and behavioral responses are observed in everyday life situations in which the respondent may have to justify his actions or be influenced by group pressures. Direct evidence on this point is provided by Warner and DeFleur (1969), who found that in a community opposing integration, low-prejudice subjects behaved more consistently when their overt behaviors were to be kept confidential, and that high-prejudice subjects behaved more consistently when their behaviors were to be made known. 
On the other hand, if a significant person, e.g., an investigator, is present both when attitudes are assessed and at the time of the behavioral measure, inconsistency should consequently be reduced. Fazio (1968) reports a relatively high attitude-behavior correlation coefficient of .47 when subjects' responses to a question about "large ugly bugs" were immediately followed by a handling test. The relatively close correspondence between attitudes toward fair employment legislation and petition-signing behavior obtained by Kamenetsky, et al. (1956) may be related to the fact that the instructor allowed a petitioner to use class time to request signatures, thus implying his approval of the petition. The instructor later administered the attitude measure to the same class. Also, in discussing their finding that authoritarians were more deferential with Negroes than non-authoritarians, Katz and Benjamin (1960) mention that "the unbiased behavior of the white $E$. . . may have introduced strong restraints against open expression of anti-Negro sentiments [p. 453]."

Subjects, when asked to explain their behaviors, often mention their thoughts about other people who are important to them. Carr and Roberts (1965) report that some of the Negro students said they did not participate in demonstrations because of parental pressures; others attributed their participation to persuasion by fellow students. DeFleur and Westie (1958) report that subjects readily mentioned the opinions of peer or family groups as factors influencing whether they signed the photographic releases. And Bellin and Kriesberg (1967) found that respondents' perceptions of whether friends and relatives approved of public housing was a useful predictor of applications for the housing.

Normative prescriptions of proper behavior. Social norms and role requirements, whether internalized by the individual or externally enforced, may contribute to inconsistency in a number of different ways (Brookover \& Holland, 1952; Chein, 1949; Cook \& Selltiz, 1964; DeFleur \& Westie, 1963; Deutsch, 1949; Fendrich, 1967; McGrath, 1964). Fendrich (1967) believes that subjects may assume different roles when verbal and overt behavioral responses are elicited, and that this helps to account for inconsistency. He found a strong relationship between attitudes and behaviors when subjects were asked to commit themselves to various interpersonal behaviors with Negroes prior to the attitude measurement, but a weak relationship when subjects responded to the attitude measure first. According to Fendrich, the usual attitude measurement situation is defined by the respondent as somewhat artificial and "play-like," in that the verbal responses are not constrained by consideration of external events or forces. However, actually engaging in behaviors or making a commitment to engage in be- 
haviors evokes a reflection upon the events or forces which may later bear upon the respondent. Thus Fendrich believes subjects who were first exposed to the commitment questionnaire defined their roles quite similarly in the interview and overt behavior situations, but that those who first responded to the attitude questionnaire played a role which differed from the one assumed when they were faced with the overt behavioral situation. Consistent with this point, Linn (1965) has suggested that his subjects' liberal attitudes reflected the prevailing norms of the "university subculture," while their unwillingness to sign photographic releases reflected a more strongly reinforced and tested norm of the broader society. And Warner and DeFleur (1969) report that when overt behaviors involving Negroes were highly visible to a community opposing integration, low-prejudice subjects were much more willing to engage in behaviors which maintained social status differences between whites and Negroes than to engage in behaviors which reduced status differences.

Competing role requirements may also exist within a single situation, and this conflict may lead to inconsistency. An example would be the businessman who professes great concern for close family ties and who experiences conflicting expectations about spending time with his family versus doing extra at the office. Culture-wide norms may also influence inconsistency by inhibiting expression of negative attitudes. It is expected, for example, that one should be polite to those whom he does not like.

Alternative behaviors available. Insko and Schopler (1967) have pointed out that for some attitudes, corresponding behaviors may not occur because opportunities for the behavior do not arise. This implies that when alternative behaviors in the overt behavioral situation are similar to those available to the subject at the time of the attitude measurement, greater consistency will result.

Although Insko and Schopler do not emphasize this point, the number of alternative behaviors is probably an important factor in attitude-behavior relationships. Consider the person who has an unfavorable attitude toward the only available newspaper in his city, yet subscribes to it. Presumably he is less inconsistent than the person who subscribes to a disliked paper when he has several to choose from. Most attitude scales greatly restrict response alternatives, and in many cases investigators also restrict the range of responses on their overt behavioral measures, particularly in the laboratory studies.

Specificity of attitude objects. A number of writers (Chein, 1949; Cook \& Selltiz, 1964; Dollard, 1949; Fishbein, 1966; Kendler \& Kendler, 1949) have pointed out that many instances of inconsistency may be due to the fact that the stimulus in verbal re- 
sponse situations tends to be very general while the stimulus in overt behavioral response situations tends to be highly specific.

For example, in many cases we have measured subjects' attitudes toward a class of people or objects, and then we have attempted to predict their behavior with respect to a particular member of that class on the basis of that attitude.

Thus we have frequently measured a subject's attitude toward Negroes, and then we have attempted to predict whether the subject would ride with, work with, or cooperate with Negroes. But it is unlikely that the subject's beliefs about the particular Negroes he comes into contact with are similar to his beliefs about Negroes in general [Fishbein, 1966, p. 206].

Stimulus dissimilarity could have contributed to inconsistency in many of the studies reported. For example, LaPiere's Chinese companions were "skillful smilers" who spoke without an accent and who travelled with a Caucasian (LaPiere, 1934). In the Kutner, et al. (1952) study, a "well-dressed and wellmannered"' Negro woman joined two white women who were already seated. The Negro confederate in Berg's (1966) study of autokinetic judgments was a student at the Ivy League university where the research was conducted. In each of these instances, the stimulus person in the behavior situation was probably quite different from subjects' broader conceptions of the minority group rated on the attitude measure.

Systematic data on this point are provided by Wicker's (1969) study of students' participation as subjects in a psychology experiment. Attitudes toward scientific research had a nonsignificant negative relationship with participation, attitudes toward psychological research had a nonsignificant positive relationship with participation, and attitudes toward participating as a subject in psychological research had a significant positive relationship with actual participation. Consistency was greater when the attitude object and the overt behavior were both highly specific than when the attitude object was general and the behavior specific. It might be expected, however, that if the object of the overt behavior were general, e.g., contributing to a fund for "the poor," then attitude toward a more general object, e.g., the poor, would be a better predictor than attitude toward a more specific object, e.g., Mexican-American migrant workers.

Unforeseen extraneous events. Kurt Lewin (1951) was pessimistic about the predictability of overt behavior from knowledge of cognitive variables such as attitudes because unforeseen events (e.g., chance meetings, accidents, illness) may intrude into the life space to disturb what might otherwise have been a predictable relationship. Such events very likely contributed to inconsistencies in 
some of the studies reviewed in the present paper, particularly when the overt behaviors occurred outside the laboratory. A sudden drop or increase in a family's income could influence whether they applied for public housing. And attendance at a group discussion meeting might be affected by a friend who happened to be in the neighborhood and "dropped by" on the night the meeting was held.

To acknowledge the influence of extraneous events in determining behavior does not require acceptance of Lewin's pessimism regarding predictability of behavior, however. For certain behaviors it should be possible to anticipate plausible external events and to ask a respondent how he would react in such situations. For example, if one wanted to predict church attendance, he might ask church members whether they would be less likely to attend church if they had weekend guests who did not attend church. A series of such questions might provide an index of how vulnerable the behavior is to extraneous events.

Expected and/or actual consequences of various acts. Verbal and overt behavioral responses may be influenced by what the individual believes will follow as a consequence of his action, or by what has followed various acts in the past, whether or not he is aware of the particular reinforcement contingency. Dollard (1949) cites as an example the employee who reports a negative attitude toward labor unions out of a fear that the investigator represents his employer. Kutner, et al. (1952) suggest that the considered possibility of legal prosecution for racial discrimination may have influenced prejudiced restaurant and tavern proprietors to serve a Negro guest, and to agree to take reservations to accommodate Negroes.

Insko and Schopler (1967) have suggested that consideration of the relevance of certain behaviors to future consequences may lead individuals to show inconsistency in current situations. Thus a person having an unfavorable attitude toward politics might nevertheless become active in a campaign if he felt his participation would in the future bring about some highly desired event, e.g., the end of a war.

In some ways, the expected and/or actual consequences of various acts may be the most fundamental of the situational factors listed in the present paper, since most of the others can be subsumed within it. For example, it can be argued that the presence or absence of certain people, and norms prescribing proper behavior are cues which help to define the contingencies in a particular situation (cf. Cook \& Selltiz, 1.964, p. 46). Also, it may be that the more similar the stimuli to which verbal and overt 
behavioral responses are made, the more likely it is that the same contingencies will exist for a favorable or an unfavorable response and thus consistency would result.

\section{Fishbein's Theory of Attitude-Behavior Relationships}

Although a number of factors in addition to attitudes have been suggested as influences upon overt behaviors, Fishbein (1967) is the only writer who has attempted to combine several factors into a systematic formulation. Fishbein's theory is an adaptation of Dulany's (1968) propositional control theory.

According to Fishbein, "Rather than viewing attitude toward a stimulus object as a major determinant of behavior with respect to that object, the theory identifies three kinds of variables that function as the basic determinants of behavior: (1) attitudes toward the behavior; (2) normative beliefs (both personal and social); and (3) motivation to comply with the norms [p. 490]." The first component, attitudes toward the behavior, depends upon (a) the individual's "beliefs about the consequences of performing a particular behavior (in a given situation) [p. 488]," and (b) his evaluation of these consequences. The second component may be broken down into two categories of normative beliefs: "(1) the individual's beliefs about what he personally feels he should do (i.e., a personal norm or rule of behavior); and (2) the individual's belief about what 'society' (i.e., most other people, his 'significant others,' etc.) 'says' he should do (i.e., a social or group norm) [p. 489]." In Fishbein's formulation, each of the normative beliefs is to be weighted by the individual's "motivation to comply with the norm, that is, his desire, or lack of desire, to do what he thinks he should do [p. 488]." Fishbein acknowledges that other variables may also affect behavior, but suggests that they operate indirectly by influencing one or more of the three basic determinants. Thus, if the behavior is to benefit a liked person, the individual's beliefs about the consequences of behavior-component (1) - will be different than if it benefits a disliked person. Motivation to comply with a norm would vary, depending upon whether persons affected by compliance are liked or disliked.

Situational variations are also held to have indirect influences on the three primary behavioral determinants. Thus whether behavior is public or private would influence beliefs about the consequences of behavior. Also, the normative beliefs would be expected to vary for different situations. Fishbein states that the relative importance of attitudes toward the behavior, personal normative beliefs and motivation, and social normative beliefs and motivation must be empirically determined. He also suggests that 
the weights may vary from behavior to behavior, and from person to person.

\section{Implications of the Present Review}

The present review provides little evidence to support the postulated existence of stable, underlying attitudes within the individual which influence both his verbal expressions and his actions. This suggests several implications for social science researchers.

First, caution must be exercised to avoid making the claim that a given study or set of studies of verbal attitudes, however well done, is socially significant merely because the attitude objects employed are socially significant. Most socially significant questions involve overt behavior, rather than people's feelings, and the assumption that feelings are directly translated into actions has not been demonstrated. Casual examination of recent numbers of this and other like journals suggests that such caution has rarely been shown.

Second, research is needed on various postulated sources of influence on overt behavior. Once these variables are operationalized, their contribution and the contribution of attitudes to the variance of overt behavior can be determined. Such research may lead to the identification of factors or kinds of factors which are consistently better predictors of overt behavior than attitudes.

Finally, it is essential that researchers specify their conceptions of attitudes. Some may be interested only in verbal responses to attitude scales, in which case the question of attitude-behavior relationships is not particularly relevant or important. However, researchers who believe that assessing attitudes is an easy way to study overt social behaviors should provide evidence that their verbal measures correspond to relevant behaviors. Should consistency not be demonstrated, the alternatives would seem to be to acknowledge that one's research deals only with verbal behavior, or to abandon the attitude concept in favor of directly studying overt behavior.

\section{REFERENCES}

AllPORT, G. W. The historical background of modern social psychology. In G. Lindzey (Ed.), Handbook of social psychology, Vol. 1, Theory and method. Cambridge, Mass.: Addison-Wesley, 1954.

Barker, R. G. (Ed.) The stream of behavior. New York: Appleton-Century Crofts, 1963

Barker, R. G. Explorations in psychological ecology. American Psychologist, 1965, 20, 1-13. 
Barker, R. G., \& Wright, H. F. Midwest and its children: The psychological ecology of an American lown. New York: Row, Peterson, 1955.

Bellin, S. S., \& Kriesberg, L. Relationship among attitudes, circumstances, and behavior: The case of applying for public housing. Sociology and Social Research, 1967, 51, 453-469.

BEM, D. J. Self-perception: An alternative interpretation of cognitive dissonance phenomena. Psychological Review, 1967, 74, 183-200.

BERG, K. E. Ethnic attitudes and agreement with a Negro person. Journal of Personality and Social Psychology, 1966, 4, 215-220.

Bernberg, R. E. Socio-psychological factors in industrial morale: I. The prediction of specific indicators. Fournal of Social Psychology, 1952, 36, 73-82.

BraY, D. W. The prediction of behavior from two attitude scales. Journal of $A b$ normal and Social Psychology, 1950, 45, 64-84.

Brayfield, A. H., \& Crockett, W. H. Employee attitudes and employee performance. Psychological Bulletin, 1955, 52, 396-424.

Brehm, J. W., \& Cohen, A. R. Explorations in cognitive dissonance. New York: Wiley, 1962.

Brookover, W. B., \& Holland, J. B. An inquiry into the meaning of minority group attitude expressions. American Sociological Review, 1952, 17, 196-202.

Campbell, A., Converse, P. E., Miller, W. E., \& Stokes, D. E. The American voter. New York: Wiley, 1960.

Campbell, D. T. Social attitudes and other acquired behavioral dispositions. In S. Koch (Ed.), Psychology: A study of a science. Vol. 6. Investigations of man as socius: Their place in psychology and the social sciences. New York: McGraw-Hill, 1963.

Carr, L., \& Roberts, S. O. Correlates of civil-rights participation. Journal of Social Psychology, 1965, 67, 259-267.

Catrell, R. B., Heist, A. B., Heist, P. A., \& Stewart, R. G. The objective measurement of dynamic traits. Educational and Psychological Measurement, 1950, 10, 224-248.

Cattell, R. B., Maxwell, E. F., Light, B. F., \& Unger, M. P. The objective measurement of attitudes. British Journal of Psychology, 1950, 40, 81-90.

Chein, I. The problems of inconsistency: A restatement. Journal of Social Issues, $1949, \mathrm{~V}, 52-61$.

Conen, A. R. Attitude change and social influence. New York: Basic Books, 1964.

Cook, S., \& Selttiz, C. A multiple-indicator approach to attitude measurement. Psychological Bulletin, 1964, 62, 36-55.

Corey, S. M. Professed attitudes and actual behavior. Journal of Educational Psychology, 1937, 28, 271-280.

DEAN, L. R. Interaction, reported and observed: The case of one local union. Human Organization, 1958, 17, 36-44.

DeFleur, M. L., \& Westie, F. R. Verbal attitudes and overt acts: An experiment on the salience of attitudes. American Sociological Review, 1958, 23, 667-673.

DeFleur, M. L., \& Westie, F. R. Attitude as a scientific concept. Social Forces, $1963,42,17-31$.

Deutsch, M. The directions of behavior: A field-theoretical approach to the understanding of inconsistencies. Journal of Social Issues, 1949, V, 43-49.

Deutscher, 1. Bibliography on the relation between sentiments and acts. Syracuse, N.Y.: Syracuse University Youth Development Center, 1966.(a)

Deutscher, I. Words and deeds: Social science and social policy. Social Problems, 1966, 13, 235-265.(b)

Dollard, J. Under what conditions do opinions predict behavior? Public Opinion Quarterly, 1949, 12, 623-632.

DulanY, D. E. Awareness, rules, and propositional control: A confrontation with S-R behavior theory. In T. R. Dixon \& D. L. Horton (Eds.), Verbal 
behavior and general behavior therapy. Englewood Cliffs, N.J.: Prentice-Hall, 1968.

Ellsworth, R. B., Foster, L., Childers, B., Arthur, G., \& Kroeker, D. Hospital and community adjustment as perceived by psychiatric patients, their families, and staff. Journal of Consulting and Clinical Psychology, 1968, 32 (5, Part 2).

Fazio, A. F. Verbal and overt-behavioral assessment of a specific fear. Journal of Consulting and Clinical Psychology, 1969, in press.

Fendrich, J. M. A study of the association among verbal attitudes, commitment, and overt behavior in different experimental situations. Social Forces, 1967, 45, 347-355.

Festinger, L. A theory of cognitive dissonance. Stanford: Stanford University Press, 1957.

FishbeIn, M. The relationships between beliefs, attitudes, and behavior. In $\mathrm{S}$. Feldman (Ed.), Cognitive consistency. New York: Academic, 1966.

Fishbein, M. Attitude and the prediction of behavior. In M. Fishbein (Ed.), Readings in attitude theory and measurement. New York: Wiley, 1967.

Freeman, L. C., \& Aatov, 'T. Invalidity of indirect and direct measures of attitude toward cheating. Journal of Personality, 1960, 38, 443-447.

Green, B. F. Attitude measurement. In G. Lindzey (Ed.), Handbook of social psychology. Vol. 1. Theory and method. Cambridge, Mass.: Addison-Wesley, 1954.

Green, J. A. Attitudinal and situational determinants of intended behavior towards Negroes. (Doctoral dissertation, University of Colorado) Ann Arbor, Mich.: University Microfilms, 1968. No. 68-2644.

GreEn, J. A. Attitudinal and situational determinants of intended behavior towards Negroes. Paper presented at the meeting of the Western Psychological Association, Vancouver, British Columbia, June, 1969.

Himmelstein, P., \& Moore, J. C. Racial attitudes and the action of Negro- and white-background figures as factors in petition signing. Journal of Social Psychology, 1963, 61, 267-272.

Hyman, $\boldsymbol{H}$. Inconsistencies as a problem in attitude measurement. Journal of Social Issues, 1949, V, 38-42.

Insko, C. A., \& Schopler, J. Triadic consistency: A statement of affectivecognitive-conative consistency. Psychological Review, 1967, 74, 361-376.

Kamenetsky, J., Burgess, G. G., \& Rowan, T. The relative effectiveness of four attitude assessment techniques in predicting a criterion. Educational and Psychological Measurement, 1956, 16, 187-194.

Katz, I., \& BenJamin, L. Effects of white authoritarianism in biracial work groups. Joumal of Abnormal and Social Psychology, 1960, 61, 448-456.

Kendler, H. H., \& Kendler, T. S. A methodological analysis of the research area of inconsistent behavior. Journal of Social Issues, 1949, V, 27-31.

Kutner, B., Wilkins, C., \& Yarrow, P. R. Verbal attitudes and overt behavior involving racial prejudice. Journal of Abnormal and Social Psychology, 1952, 47, 649-652.

LaPiere, R. T. Attitudes vs. Actions. Social Forces, 1934, 13, 230-237.

LEwIN, K. Field theory in social science. D. Cartwright (Ed.). New York: Harper, 1951.

LinN, L. S. Verbal attitudes and overt behavior: A study of racial discrimination. Social Forces, $1965,44,353-364$.

Mann, J. H. The relationship between cognitive, affective, and behavioral aspects of racial prejudice. Fournal of Social Psychology, 1959, 49, 223-228.

Malof, M., \& LoTT, A. J. Ethnocentrism and the acceptance of Negro support in a group pressure situation. Fournal of Abnormal and Social Psychology, 1962, $65,254-258$. 
McGrath, J. E. Social psychology. New York: Holt, Rinehart and Winston, 1964.

McNemar, Q. Opinion-attitude methodology. Psychological Bulletin, 1946, 43, 289-374.

Mischel, W. Personality and assessment. New York: Wiley, 1968.

Murphy, G., Murphy, L. B., \& Newcomb, T. M. Experimental social psychology. (Rev. ed.) New York: Harper, 1937.

Newcomb, T. M., Turner, R. H., \& Converse, P. E. Social Psychology. New York: Holt, Rinehart and Winston, 1965.

Newton, N., \& Newton, M. Relationship of ability to breast feed and maternal attitudes toward breast feeding. Pediatrics, 1950, 5, 869-875.

Newton, N., \& Newton, M. Psychological aspects of lactation. New England Journal of Medicine, 1967, 277, 1179-1188.

Potter, H. W., \& Klein, H. R. On nursing behavior. Psychiatry, 1957, 20, 39-46.

Raush, H. L., Dittman, A. T., \& Taylor, T. J. Person, setting, and change in social interaction. Human Relations, 1959, 12, 361-378.

Raush, H. L., Farbman, I., \& Llewellyn, L. G. Person, setting, and change in social interaction. II. A normal-control study. Human Relations, 1960, 13, 305-332.

ROKEACH, M. Attitude change and behavior change. Public Opinion Quarterly, $1967,30,529-550$.

ROKEACH, M., \& MEZEi, L. Race and shared belief as factors in social choice, Science, 1966, 151, 167-172.

Sagi, P. C., Olmstead, D. W., \& Atelsek, F. Predicting maintenance of membership in small groups. Journal of Abnormal and Social Psychology, 1955, 51, 308-311.

ShonTz, F. C. Research methods in personality. New York: Appleton-Century-Crofts, 1965.

SMith, E. W. L., \& Dixon, T. R. Verbal conditioning as a function of race of the experimenter and prejudice of the subject. Journal of Experimental Social Psychology, 1968, 4, 285-301.

Tittle, C. R., \& Hill, R. J. Attitude measurement and prediction of behavior: An evaluation of conditions and measurement techniques. Sociometry, 1967, 30, 199-213.

Vroom, V. H. Ego-involvement, job satisfaction, and job performance. Personnel Psychology, 1962, 15, 159-177.

VRoom, V. H. Work and motivation. New York: Wiley, 1964.

Warner, L. G., \& DeFleur, M. L. Attitude as an interactional concept: Social constraint and social distance as intervening variables between attitudes and action. American Sociological Review, 1969, 34, 153-169.

Webi, W. B., \& Hollander, E. P. Comparison of three morale measures: A survey, pooled group judgments, and self evaluations. Joumal of Applied Psychology, 1956, 40, 17-20.

Weissberg, N. C. On DeFleur and Westie's 'Attitude as a scientific concept.' Social Forces, 1965, 43, 422-425.

Weitz, J., \& Nuckols, R. C. The validity of direct and indirect questions in measuring job satisfaction. Personnel Psychology, 1953, 6, 487-494.

Westie, F. R. A technique for the measurement of race attitudes. American Sociological Review, 1953, 18, 73-78.

WICKER, A. W. The relationship between attitudes and behavior as a function of specificity of the attitude object. Unpublished manuscript, University of Wisconsin, Milwaukee, 1969.

Woodmansee, J. J., \& Cook, S. W. Dimensions of verbal racial attitude: Their identification and measurement. Fournal of Personality and Social Psychology, $1967,7,240-250$. 
Copyright of Journal of Social Issues is the property of Blackwell Publishing Limited and its content may not be copied or emailed to multiple sites or posted to a listserv without the copyright holder's express written permission. However, users may print, download, or email articles for individual use. 